\title{
MUSICOTERAPIA SOCIAL E COMUNITÁRIA E PROCESSOS DE SUBJETIVAÇÃO POLÍTICA
}

\author{
MUSICOTERAPIA SOCIAL Y COMUNITARIA \\ $\Upsilon$ PROCESOS DE SUBJETIVACIÓN POLÍTICA \\ SOCIAL AND COMMUNITY MUSIC THERAPY \\ AND POLITICAL SUBJECTIVATION PROCESSES
}

\author{
Andressa Dias Arndt ${ }^{1}$ e Katia Maheirie ${ }^{2}$
}

${ }^{1}$ Universidade Estadual do Paraná, Curitiba/PR, Brasil

${ }^{2}$ Universidade Federal de Santa Catarina, Florianópolis/SC, Brasil

RESUMO: Este artigo apresenta reflexões e análises sobre a Musicoterapia Social e Comunitária na América Latina e apresenta alguns deslocamentos na posição de musicoterapeutas que podem possibilitar alargamentos no campo de possíveis, tanto no âmbito da Musicoterapia Social e Comunitária como no campo de existência das pessoas. As informações que aqui analisamos foram construídas por meio de entrevistas e pesquisa no cotidiano de trabalho de musicoterapeutas latino-americanos/as. Acreditamos que alguns deslocamentos da posição de musicoterapeutas podem impulsionar a criação de processos de subjetivação política. A partir da perspectiva de Jacques Rancière, compreendemos que é por meio de processos de subjetivação política que lugares identitários podem ser tensionados, perturbando assim as formas de pensabilidade, audibilidade e visibilidade operantes nos cotidianos com os quais temos trabalhado. Por fim, apresentamos a possibilidade da criação artística no processo de alargamento das possibilidades de ser, pensar e agir.

PALAVRAS-CHAVE: Musicoterapia social e comunitária; Subjetivação política; Música.

RESUMEN: Este artículo presenta reflexiones y análisis sobre la Musicoterapia Social y Comunitaria en América Latina y presenta algunos cambios en la posición de musicoterapeutas que pueden posibilitar expansiones en el campo de posibilidades, tanto en el contexto de la Musicoterapia Social y Comunitaria como en el campo de existencia de las personas. La información que analizamos aquí se construyó a través de entrevistas e investigaciones en el trabajo diario de los musicoterapeutas latinoamericanos/as. Creemos que algunos cambios en la posición de musicoterapeutas pueden impulsar la creación de procesos de subjetivación política. Desde la perspectiva de Jacques Rancière, entendemos que es a través de los procesos de subjetivación política que se pueden tensar los lugares identitarios, perturbando así las formas de pensabilidad, audibilidad y visibilidad que operan en la vida cotidiana con la que venimos trabajando. Finalmente, presentamos la posibilidad de la creación artística en el proceso de ampliar las posibilidades de ser, pensar y actuar.

PALABRAS CLAVE: Musicoterapia social y comunitaria; subjetivación política; Música.

ABSTRACT: This article presents reflections and analyzes on Social and Community Music Therapy in Latin America and presents some shifts in the position of music therapists that can enable expansions in the field of possibilities, both in the context of Social and Community Music Therapy and in the field of people's existence. The information we analyze here was built through interviews and research in the daily work of Latin American music therapists. We believe that some shifts in the position of music therapists can drive the creation of political subjectivation processes. From the perspective of Jacques Rancière, we understand that it is through processes of political subjectivation that identity places can be tensioned, thus disturbing the forms of thinkability, audibility and visibility operating int the daily lives with which we have been working. Finally, we present the possibility of artistic creation in the process of expanding the possibilities of being, thinking and acting.

KEYWORDS: Social and Community Music Therapy; Political subjectivation; Music. 


\section{Introdução}

Este artigo apresenta um olhar sobre as ações de musicoterapeutas no processo de criação e fortalecimento de uma Musicoterapia de base social e comunitária na América Latina. Neste texto, vamos discorrer sobre alguns deslocamentos nas posições de musicoterapeutas, que podem acontecer por meio de processos de desidentificação com o lugar clássico de musicoterapeuta e de uma identificação impossível com a existência das pessoas com as quais trabalham. O conceito de identificação impossível proposto pelo filósofo franco-argelino Jacques Rancière (Rancière, 2010a) será desenvolvido ao longo deste texto. A travessia desses processos de desidentificação/identificação impossível pode impulsionar a abertura de um terceiro momento, que diz sobre adotar uma postura apta a contribuir no processo de alargamento no campo de possibilidades, em um duplo sentido: em se tratando da ampliação das possibilidades de se pensar e fazer Musicoterapia e no sentido de calcar como objetivo do trabalho a mediação nos processos de ampliação das possibilidades de ser, pensar e sentir no cotidiano das pessoas partícipes.

A Musicoterapia é um campo de saber e prática que desde a metade do século passado tem investido no processo de construção de conhecimento. Durante essas poucas décadas de história, musicoterapeutas têm atuado em diversos espaços, com distintas parcelas da população, e criado diferentes caminhos para os múltiplos objetivos construídos. A despeito de uma trajetória marcada pela ênfase em práticas de cunho individualista e orientado por um paradigma biomédico, desde a década de 1990 constatamos que há no campo da Musicoterapia um crescente de práticas que partem de uma perspectiva social e comunitária (Arndt, Cunha, \& Volpi, 2016; Arndt \& Maheirie, 2019; Cunha, 2016; Oselame \& Carvalho, 2013). Tal entrada tem impulsionado a criação e fortalecimento de uma comunidade de musicoterapeutas sociais e comunitários que têm investido em outras formas de pensar e fazer Musicoterapia.

Em nosso ponto de vista, a Musicoterapia Social e Comunitária é um campo de saber e prática que assinala a condição criativa do humano e aposta que, a partir da ampliação das possibilidades de construir objetivações artísticas musicais, também o campo de ampliação das possibilidades de (re)criar a existência se alarga.

Com a motivação de perseguir como têm sido criados os caminhos de desenvolvimento de uma Musicoterapia Social e Comunitária na América Latina é que realizamos entrevistas com alguns/as musicoterapeutas e participamos de seus cotidianos de trabalho.

Durante o processo de construção de informações, tivemos a oportunidade de conhecer muitos trabalhos que têm acontecido em território latino-americano e que adotam perspectivas sociais e comunitárias de saber e prática. Diante das experiências que pudemos ter e das informações que construímos na travessia da pesquisa, analisamos que há nesses fazeres uma preocupação com as formas de audibilidade e visibilidade operantes nos contextos das pessoas com as quais os/as musicoterapeutas trabalham e também uma inclinação ao investimento nas relações das pessoas como possibilidade de alargamento da existência. Com isso, criamos uma linha temática para este artigo, que tratará de perseguir uma compreensão sobre alguns deslocamentos na posição dos/as musicoterapeutas. Tais deslocamentos podem potencializar as experiências musicais em Musicoterapia de modo a contribuir para o tensionamento de lugares cristalizados e assim, promover alargamentos nas fronteiras dos possíveis. 


\section{Caminhos percorridos}

O desenho que elegemos para esta escrita busca perseguir a criação de novos possíveis (Paulon \& Romagnoli, 2010). Adotamos diferentes procedimentos para construção de informações, tais como a realização de entrevistas abertas com questões norteadoras e a observação no cotidiano de trabalho de musicoterapeutas que atuam na Argentina, na Colômbia e no Brasil.

Neste texto nos dedicamos de modo mais aprofundado ao processo de análise das informações construídas a partir das entrevistas realizadas com 59 musicoterapeutas de diversos países da América Latina. A realização foi de modo individual, por meio de chamadas de vídeo/áudio no Skype e/ou WhatsApp, ou respondidas por escrito e enviadas por e-mail, quando a pessoa entrevistada assim desejou. Realizamos apenas uma entrevista de modo presencial, com um coletivo de musicoterapeutas comunitários que atua em São Paulo, Brasil. Todas as entrevistas foram transcritas e as realizadas em espanhol foram também traduzidas para o português.

A etapa de pesquisa no cotidiano de trabalho de musicoterapeutas envolveu a permanência de uma das pesquisadoras durante uma semana em Bogotá, na Colômbia. Durante essa experiência a pesquisadora pôde acompanhar o trabalho desenvolvido por um musicoterapeuta com crianças em escolas de zona rural, em uma instituição que acolhe crianças e jovens que sofreram violação de direitos e acompanhando uma dupla de musicoterapeutas que trabalha com pessoas que viveram experiências de conflito armado. Em Buenos Aires, na Argentina, durante uma semana acompanhamos trabalhos da Musicoterapia Social e Comunitária realizados em centros de convivência, escola pública e ocupação por moradia. Realizamos também o acompanhamento de um dia de trabalho do coletivo de musicoterapeutas comunitários acima mencionados, dentro de uma ocupação por moradia.

Nosso processo de construção de informações e análise assumiu uma inspiração nas propostas do Método da Igualdade, de Jacques Rancière (2009a; 2014a). Com isso, escolhemos pensar o método como um caminho criado pelo/a pesquisador/a, que dá notícias do lugar em que se está e o projeta para os lugares para os quais deseja ir, no entanto, sem marcar a absoluta previsibilidade do destino. Assumir essa inspiração nos aproximou de uma postura que pretendeu suspender, ainda que temporariamente, a distribuição hierárquica das existências e dos saberes. No método proposto por Rancière encontramos uma proposta de mundo pautada em uma disposição igualitária das capacidades, buscando assim "borrar as distâncias entre os níveis de discursos" (2014b, p. 130). Compreendemos que o Método da Igualdade prevê a criação de cenas polêmicas, capazes de levantar suspeitas diante do convencionalmente posto.

Em nosso processo de análise pudemos perceber uma inclinação de alguns/mas musicoterapeutas latino-americanos/as para pensar as questões de audibilidade e visibilidade que permeiam os contextos nos quais trabalham. De igual modo, notamos que há uma aposta em comum: a de criação e fortalecimento de relações como forma de inauguração de outras possibilidades para o ser, pensar e agir. Sendo assim, nosso foco neste trabalho é voltar nosso olhar para o coletivo.

Neste texto, ao invés de trabalharmos somente com aquilo que mais nos sobrevém, que é mais recorrente nas informações que construímos, nos lançamos em busca dos atos insólitos. Com isso, buscamos apontar alguns deslocamentos no trabalho de musicoterapeutas 
na América Latina, os quais têm possibilitado promover encontros, mediados por fazeres musicais, capazes de tensionar os lugares postos e, assim, contribuir para invenção de margens mais alargadas para a existência, tanto em âmbito singular quanto coletivo.

A partir da criação de uma narrativa sobre tais aspectos dos saberes e fazeres da Musicoterapia em contextos comunitários e sociais na América Latina, pretendemos colaborar com o movimento de criação de cenas dissensuais no campo estabelecido da Musicoterapia, buscando, por meio do tensionamento com o que está posto, projetar outros possíveis.

\section{Subjetivação política e Musicoterapia}

A entrada de perspectivas sociais e comunitárias em Musicoterapia convoca questionamentos e, consequentemente, move uma parcela de musicoterapeutas a um afastamento de um lugar convencional de prática. Interessa-nos tecer um olhar inicial para como tem sido a postura desses/as musicoterapeutas diante dos desafios evocados por atuações em contextos sociais e comunitários. Nosso intento é analisar tais movimentos e perscrutar ações que possam alimentar processos de subjetivação política.

Compreendemos o conceito de subjetivação política como o meio pelo qual são postas em questão as formas sensíveis de se partilhar o mundo comum, apontando para desvios possíveis no curso normativo do cotidiano (Rancière, 1996; 2010a). Para que processos de subjetivação política aconteçam, é necessário haver dois movimentos. Um é de desidentificação com o lugar identitário convencionalmente posto e com o lugar de saber hierarquicamente marcado. O outro movimento prevê um lance de identificação impossível, com a existência de sujeitos que historicamente são contados como inferiores, subalternos. O processo de subjetivação política é orientado por uma lógica de igualdade de capacidades, e persegue a ampliação das formas de ser, pensar e agir de toda uma identidade mais ampla, compreendendo que

toda subjetivação é uma desidentificação, o arrancar à naturalidade de um lugar, a abertura de um espaço de sujeito onde qualquer um pode contar-se porque é o espaço de uma contagem dos incontados, do relacionamento entre uma parcela e uma ausência de parcela. (Rancière, 2010a, p. 48)

\section{Movimento de desidentificação}

Ao transitar por esses deslocamentos, musicoterapeutas têm se desidentificado com a definição clássica do ser musicoterapeuta, aquele narrado como "alguém que toma o compromisso de ajudar um cliente com uma meta relativa à saúde através da música" (Bruscia, 2016, p. 56). Durante entrevista, uma musicoterapeuta comenta: "o que eu digo é que eu sou musicoterapeuta, mas, não faço terapia” (Participante 1, entrevista pessoal, 18 de fevereiro de 2018). Com isso, alguns/as musicoterapeutas se sentem impulsionado/as a adotarem um posicionamento "o mais afastado de pretensões para com o outro... sem pretensões do que quero que o outro faça... afastada das pretensões de que o outro seja o que eu quero que seja" (Participante 2, entrevista pessoal, 17 de maio de 2018). 
Consideramos esse primeiro recuo um passo importante no processo de se despir de estatutos convencionalmente postos para esse lugar de musicoterapeuta.

Por meio do processo de renúncia de ocupação de um lugar clássico de musicoterapeuta e de um lugar de saber superiorizado, é importante refletimos sobre "como eu entro na comunidade e permito me impregnar pelos sons, os cheiros, os ritmos, as formas de falar, as culturas" (Participante 2, entrevista pessoal, 17 de maio de 2018). Com isso, a questão que nos interessa não é tanto sobre o trabalho acontecer dentro de uma comunidade e não em um consultório, por exemplo, mas sim, o que nos instiga é pensar sobre os modos de estar, de sentir, de pensar, de agir dos/as musicoterapeutas, pois é a composição desses elementos que irá desenhar uma posição com margens mais alargadas, ou não, para a criação de saberes e fazeres em Musicoterapia.

Nas palavras de Participante 3, musicoterapeuta que reside e trabalha no México, "ser musicoterapeuta... é uma atitude" (entrevista pessoal, o9 de outubro de 2018). A palavra atitude nos remete a uma forma de dispor o corpo no desenho das relações estabelecidas, uma postura em relação ao campo do sensível, ou seja, em relação às formas reguladas de se pensar, sentir, escutar e ver o humano.

O primeiro movimento se encarna, portanto, nesse processo de desidentificação com o lugar convencionalmente posto, relevante para o processo de alargamento das possibilidades de se fazer e pensar Musicoterapia.

\section{Movimento de identificação impossível}

Consideramos que outro deslocamento nesse processo de alargamento das possibilidades de se pensar e fazer Musicoterapia ocorre por meio de uma identificação outra. Ato importante na composição de um processo de subjetivação política.

A Participante 3 nos conta em entrevista que, quando iniciou a formação em Musicoterapia na Colômbia, decidiu adentrar de forma radical a comunidade que pretendia pesquisar:

o bairro me convocou... o bairro sou eu, por mais estudos que eu tenha, para mim, a rua é uma escola permanente, real. Em Soacha (município que compõe a região metropolitana de Bogotá na Colômbia), eu era parte de um coletivo... esse foi o lugar onde eu acreditei no trabalho comunitário. Embora seja verdade que o discurso, a literatura, a bibliografia em relação à musicoterapia são profundas, eu acredito na rua... os processos sociais, e as questões de justiça social é algo que me atravessa. (Participante 3, entrevista pessoal, 09 de outubro de 2018)

Na narrativa da Participante 3, vemos um segundo movimento importante no processo de subjetivação política: o de lançar-se a uma outra identificação, uma identificação com um outro lugar, movimento nomeado por Rancière (2014a) de identificação impossível. Encontramos movimento semelhante na narrativa de uma musicoterapeuta que trabalha dentro de uma ocupação por moradia na cidade de São Paulo:

durante o processo a gente tinha diversas expectativas, ideias, planos e objetivos, e muito disso a gente foi vendo... não dava certo como a gente tinha programado, e o ponto principal é que não era um ambiente controlado, diferente de 
uma clínica ou de uma instituição... Dentro da ocupação a gente tinha um monte de elementos imprevisíveis... a maioria dos encontros acontecia no chão mesmo, nas vielas da comunidade, a gente colocava uma lona no chão e aí ia chamando as crianças, as crianças iam se reunindo... A gente começou a entender que seria impossível trabalhar dentro dessa proposta e ao mesmo tempo estar isento ou ignorar a realidade política, social, daquele espaço. A gente entendeu que nosso trabalho, além de sermos musicoterapeutas, a gente tinha que ter um olhar mais amplo para essas questões de direitos humanos, para questão da política implantada, para tentar entender o que que já estava acontecendo lá. (Participante 4, entrevista pessoal, 16 de agosto de 2018)

Nas palavras da Participante 4, musicoterapeuta do coletivo estudado, fica explícito como a posição que ela adota junto à comunidade na qual trabalha possibilita que passe a figurar no cotidiano de trabalho a necessidade de uma implicação outra com as condições de existência que operam no território em que se atua. Há uma identificação com o campo de (im)possíveis que se constroem por meio das condições sociais, culturais, históricas vigentes no território, levando-a a constatar que "em alguns momentos a gente se via também como ativistas... a gente criou um vínculo tão forte de confiança da comunidade, que nos viam não só como musicoterapeutas, mas sim como parceiros da luta deles" (Participante 4, entrevista pessoal, 16 de agosto de 2018).

Durante o dia que passamos acompanhando o trabalho do coletivo de musicoterapeutas, chamou nossa atenção a forma horizontalizada de se criar relações com a comunidade de uma ocupação por moradia. Uma moradora que estava dentro de sua casa, ao perceber a chegada dos/as musicoterapeutas nas vielas do território, acomodou o rosto na janela, nos viu passando e nos convidou para o almoço. As crianças se aproximavam sorrindo e chamando alguns/mas dos/as integrantes do coletivo pelo nome. Todos esses pequenos elementos nos dão notícias das relações horizontalizadas que ali têm se instaurado.

Nas narrativas das Participante 3 e 4 encontramos algumas cenas de uma identificação impossível. As musicoterapeutas não se tor nam uma das pessoas da comunidade na qual atuam, mas perseguem um viver possível num entre mundos, assumindo um lugar de "sujeitos políticos no intervalo ou no hiato entre duas identidades" (Rancière, 2014b, p. 08).

Compreendemos que esses dois deslocamentos, a desidentificação e a identificação impossível, são elementos constituintes na criação de processos de subjetivação política. Com tais ações, lugares identitários podem ser postos em tensão e novos lugares podem passar a entrar em cena.

\section{Tensionamentos possiveis}

A aventura dessa travessia de deslocamentos identitários inclina o trabalho de alguns/mas musicoterapeutas a assumir um compromisso com a produção de novas margens, tanto para o campo da Musicoterapia quanto para o campo da existência coletiva. Por meio da criação de outros espaços possíveis para a vida se arquitetar e novos sonhos para gestar, a aposta dos fazeres passa a ser de que há possibilidade de "construção de novas formas da vida comum” (Rancière, 2010a, p. 36). 
Com isso, a partir de nosso entendimento, há uma relevância ao admitir o conceito de partilha do sensível como nota importante a figurar no cenário da Musicoterapia Social e Comunitária na América Latina. Compreendemos o conceito de partilha do sensível a partir de Rancière (2009b) como tendo um duplo lance: de um lado como se dá a participação em um mundo comum e, de outro, como acontecem as separações, ou seja, quem toma parte nos tempos e espaços e quais posições são ocupadas na arena cotidiana. Nas palavras de Rancière (2010a, p. 21), a partilha do sensível diz dessa "distribuição e essa redistribuição dos lugares e das identidades, esse corte e recorte dos espaços e dos tempos, do visível e do invisível, do barulho e da palavra”.

A Musicoterapia pode, dessa forma, assumir o contexto social como sendo o palco em que se apresentam cenas que atestam lugares conflitivos, essa arena em que constantemente se opera um conflito de competências. Desse modo, podemos nos aproximar de um lugar de profissional que atua no campo do político, compreendendo-o como um campo de embate entre dois polos. Um, regido pelo pressuposto da igualdade, outro regido pelo mundo das instituições, da norma. Ao polo regido pela igualdade, Rancière chama política (Rancière, 2014b).

A igualdade, a partir de Rancière (2002), pode ser compreendida como axioma, e não como projeto ideal. Todo sujeito é humano, portanto, o autor parte da igualdade das capacidades. Esse princípio de igualdade carrega as diferentes possibilidades de existir, caracterizadas por singularidades sociais, históricas, culturais e pode ser verificada. Podemos compreender a verificação da igualdade como um "instrumento articulador de nomes, lugares e posições em formas e relações não perceptíveis ainda... não são necessariamente novas experiências, mas a alteração e a reconfiguração do campo no qual as experiências estão dadas" (Marques \& Prado, 201 8b, p. 51 ). Os atos de verificação da igualdade atestam que todo ser é portador de palavra, de logos, ainda que, por meio das configurações sensíveis instauradas, algumas palavras sejam escutadas como ruído e outras como voz. Afinal

o logos nunca é apenas a palavra, porque ele é sempre indissoluvelmente a contagem que é feita dessa palavra: a contagem pela qual uma emissão sonora é ouvida como palavra, apta a enunciar o justo, enquanto uma outra é apenas percebida como barulho. (Rancière, 1996, p. 36)

De outro lado no campo do político está, portanto, o campo das governanças, do mundo normativo, das instituições, das leis, o espaço em que a distribuição dos corpos opera. A esse polo, Ranciére chama polícia. Importante marcar que para o autor não há um juízo de valor entre os dois polos, um só existe em relação ao outro.

Durante a realização desta pesquisa, analisamos que algumas formas de se pensar e fazer Musicoterapia Social e Comunitária têm cada vez mais perseguido experiências emancipatórias. A partir de Rancière (2014a), compreendemos que os processos de emancipação envolvem a criação de atos que promovam ruptura na ordem posta, denunciando um dano sentido por uma parcela da população que sofre por não ter sido contada na partilha dos lugares legitimados, por não ter sido considerada como igual. Portanto, a "política, de fato, não é o exercício do poder, ou a luta pelo poder" (Rancière, 2010a, p. 20), a política acontece quando são criados atos de verificação da igualdade.

Propomos articular uma reflexão em torno do princípio de igualdade a partir da experiência narrada por um musicoterapeuta brasileiro: 
teve um ano que a gente conseguiu uma van, e eu levei dezoito jovens que nunca tinham visto o mar, e a gente fez quatro shows no litoral de São Paulo. Eles fizeram o show, e isso pra eles foi duma potência... Eles diziam: "éporque agora eu sou igual, eu estou me aproximando pra ser igual a todos, quase todo mundo que eu conheço já viu o mar, eu nunca tinha visto, agora eu já vi o mar também." (Participante 5 , entrevista pessoal, 10 de setembro de 2018)

A Musicoterapia pode, portanto, coadunar com a promoção de atos que verifiquem a igualdade de qualquer ser falante para com qualquer outro ser falante e, assim, investir na mediação de processos de emancipação. Com a afirmativa "agora eu sou um igual", podemos ter alguma notícia sobre as formas de distribuição dos corpos na partilha que opera o campo das sensibilidades na vida desses sujeitos. Ao tomar a igualdade como axioma, renunciamos à ideia de que é preciso conquistar um lugar de igualdade. Antes, é necessário atestar a igualdade que constitui o humano.

Marcamos, dessa forma, que atuar no campo do político é perseguir a criação de experiências emancipatórias, em que os sujeitos se deslocam de seus lugares cristalizados em direção a outros possíveis. Em linhas gerais, a emancipação está "ligada ao acesso e à construção de um mundo comum” (Marques \& Prado, 2018b, p. 61).

Importante marcar que, para Rancière (1996), assim como para Angela Marques e Marco Prado (2018a; 2018b), o comum é compreendido como estando em constante movimento, em um contínuo desenhar-se conforme as cenas de verificação de igualdade se criam, atestando quem tem parte no comum, qual parcela da população tem sua voz ouvida e validada na partilha da vida, e quem tem sua voz escutada como barulho. Assim, mais do que trazer à baila os sem parte, o que está em questão é "a apresentação sensível deste comum” (Rancière, 1996, p. 13). Ou seja, a construção de um em comum prevê o constante questionamento e um constante tensionamento sobre as fronteiras que delimitam os lugares e não lugares, atentando à "maneira como são repartidas as formas de exercício e controle do exercício desse poder comum” (Rancière, 1996, p. 20).

\section{A criação artística e os fazeres de musicoterapeutas sociais e comunitários}

No decorrer da realização desta pesquisa, analisamos que tais deslocamentos na posição de alguns/mas musicoterapeutas sociais e comunitários têm contribuído para a promoção de espaços mediados por fazeres musicais capazes de tensionar o sensível e os lugares identitários postos.

A partir das obras de Jacques Rancière, compreendemos que uma das formas da arte tocar a política é em sua abertura à possibilidade de ocupação de lugares outros, quando sujeitos destinados a ocupar não lugares, lugares não legitimados, lugares subalternizados, tensionam essa lógica e, assim, o campo de possíveis pode ser alargar. Um musicoterapeuta relata que um dos trabalhos que realizou em uma comunidade envolveu mediar a participação de um coletivo em um festival na Avenida Paulista:

Eles nunca tinham ido para a Avenida Paulista, que é uma avenida principal aqui em São Paulo. Então a gente conseguiu ir para a Avenida Paulista que era um Festival que eles iriam participar, eles participaram e ganharam o Festival. Foi emocionante! A gente filmou, foi lindo, eles foram crescendo. Teve uma me- 
nina que através desse processo, ela entrou na USP (Universidade de São Paulo). Ela foi fazer ECA que é a Escola de Comunicação e Artes da USP. Agora ela conseguiu uma bolsa, está indo para Portugal... Ela é um marco na comunidade, ela virou um exemplo, ela é um totem. (Participante 5, entrevista pessoal, 10 de setembro de 2018)

Quando sujeitos se põem em questão e ousam pensar em um horizonte outro, ao sentirem-se a partir de outra posição possível, assinalam a capacidade de criação possível a todos/as e a qualquer um/a. Compreendemos que uma das possibilidades de trabalho da Musicoterapia Social e Comunitária pode ser a de mediar processos para que os sujeitos possam se compreender como capazes de criar um mundo outro.

A possibilidade criadora do humano não se limita a alguns seletos sujeitos, na cotidianidade das pessoas "existem todas as condições necessárias para criar" (Vigotski, 1930/2014, p. 05). Musicalmente isso pode se dar a partir da experimentação de diferentes combinações de elementos sonoro-musicais, em encontros de criação e partilha coletiva. Durante o fazer musical as pessoas podem criar melodias, (re)criar tecidos musicais já conhecidos, combinar diferentes timbres e ritmos, envolverem-se em um processo contínuo de fazer e (re)fazer.

A atividade artística extrai elementos da concretude da vida para, por meio da ficcionalidade, transformar tais elementos e, uma vez objetivados, voltam "outra vez à realidade... trazendo consigo uma força ativa nova, capaz de transformar essa mesma realidade, fechando-se assim, o ciclo da atividade criativa da imaginação humana” (Vigotski, 1930/2014, p. 20).

$\mathrm{Na}$ narrativa de um musicoterapeuta entrevistado, ele nos abre a seguinte questão: "Quando a criança vem chegando com o instrumento e fala: 'deixa eu tocar?', quantos sonhos ela está querendo tocar quando pede o instrumento pra gente?" (Participante 6, entrevista coletiva, 04 de novembro de 2018). Podemos pensar o ato de sonhar com uma produção imaginativa, que pode não se encerrar na produção artística-musical ali criada, antes, pode pôr em movimento a existência e as condições históricas ali operantes, afinal "a ficção fia mundos" (Costa, 2014, p. 553).

Nesse sentido, compreendemos que há uma potência quando os fazeres musicais coletivos conseguem extrapolar os limites de tempo e espaço do encontro e passam a afetar o cotidiano. Quando passam a atuar na concretude da vida de uma comunidade, as objetivações artísticas podem se inscrever como cenas que perturbam as formas de visibilidade, pensabilidade e audibilidade vigentes. Participante 5, musicoterapeuta atuante na capital paulista, conta-nos que, às vezes, as crianças e jovens com os quais trabalha lhe dizem:

"minha mãe me via como um marginal, como um vagabundo, daí ela me viu naquele show que a gente fez no dia das crianças”. Então eu considero a apresentação externa um processo importante também, com esses jovens. De alguma forma a comunidade precisa saber o que está acontecendo... alguém vai olhar pra ele, vai admirar ele, vai ressignificar o olhar com ele. (Participante 5, entrevista pessoal, 10 de setembro de 2018)

A arte pode perturbar o sensível e alargar não só a existência de um/a, mas sim de toda e qualquer pessoa. Durante entrevista coletiva, uma musicoterapeuta afirma que o trabalho da Musicoterapia na Ocupação por moradia em que atua 
É resgate também... de um lugar de fala. Eu acho que tem muito a ver... com os adultos perceberem a potência das crianças também, e dos jovens. E olharem para aqueles jovens e crianças como seres produtores também, de arte, de resistência, como força dentro da comunidade. Pensar aquilo como potência dentro da luta da comunidade. (Participante 4, entrevista coletiva, O4 de novembro de 2018)

Com isso, notamos que a implicação do trabalho está em promover encontros que criem cenas polêmicas, cenas de dissenso, que denunciam um dano sentido por uma parcela dos sem-parte, uma vez que é no movimento de montagem e desmontagem das cenas que se tensionam as formatações, por meio da apresentação de novos reenquadres possíveis (Marques \& Prado, 2018a).

Um musicoterapeuta entrevistado relata que, ao trabalhar com jovens que cometeram ato infracional, recebia-os para o encontro e comumente escutava discursos como "sou menor de idade, sou preto, sou pobre e, ao longo dos encontros, pôde perceber um deslocamento no discurso dos jovens, quando o recebiam e comentavam "o assistente social, o psicólogo, eles veem que eu sei fazer uma música, que consigo cantar. Mudou, agora as pessoas me olham diferente" (Participante 5, entrevista pessoal, 10 de setembro de 2018).

É essa abertura para um mundo outro possível que torna a arte política. A arte tem essa potência, não por guardar mensagens políticas engajadas em si, mas por provocar no espectador uma necessidade de resposta por meio das afecções da experiência estética, e, de igual modo, criar questões para o campo do vivido. Ou seja, não se encerra no ambiente particular de um sujeito, abre o campo de possíveis para toda e qualquer existência.

Por meio da criação artística, da ficção, o humano pode irromper para novos possíveis, deslocando lugares historicamente postos, uma vez que "a imaginação é o poder de criar formas, e a política é um assunto de imaginação... A imaginação entra em ação para construir, delimitar, organizar um espaço, dar outro ritmo ao tempo" (Rancière, 2018, p. 9). Com isso, o alargamento da existência se dá para além da vida do sujeito, reverbera, afeta o contexto, interfere no cotidiano, porque ao assinalar a expansão de sua possibilidade de existir, o faz não só a si e não o faz de modo solitário, marca a possibilidade de invenção que constitui a todos/as e a qualquer um/a.

Os contextos sociais e comunitários nos quais a Musicoterapia tem adentrado podem se constituir como espaços de produção de conhecimento, agenciados pelos/as participantes, mediados pelo fazer musical. Assim, o ato de fazer música é uma experiência concomitantemente reflexiva e geradora (Blacking, 2007; Maheirie, 2003). É nessa abertura à ação que reside a potência da música. Por ser arte, a música pode mover atos, convocar respostas, perturbar posições. Assim, o fazer musical não somente retrata o real, transmite informações ou nos contagia com sentimentos. Para além disso, a arte pode dar outras formas aos sentimentos.

As experiências artísticas têm a potência de nos levar à destruição do sentimento, à transformação dele e sua superação. Lev Vigotski (1925/1998) chama esse processo de catarse, em que, por meio da vivência de um tipo de curto-circuito de emoções, presente na contradição entre forma e conteúdo da obra artística, poderá abrir para a ação, atuando no corpo e por meio dele no processo de lançar-nos a outras atividades criativas, no âmbito singular e coletivo. 
O fazer musical é, portanto, uma atividade humana, complexa, que envolve aspectos relacionais, culturais, sociais, cognitivos, afetivos, volitivos e emocionais. É um tipo de atividade determinada e determinante do contexto, possibilitando a construção de diferentes significados e sentidos constituídos histórica e culturalmente. Partimos de uma perspectiva sobre o fazer musical que o compreende como uma capacidade possível a todos/as, superando um pensamento que separa aqueles/as que fazem música dos/as que não são aptos/as para tal. Christopher Small (1998) afirma que tal cisão roubou nossa possibilidade de fazer música. No entanto, marcamos o fazer musical como possível a qualquer um/a (Aragon, 2019).

Fazer música é, portanto, uma ação dialética, que transita entre atos de subjetivação e objetivação. Por um lado, a arte é um trabalho de ficção, um trabalho imaginativo, por outro lado é também uma experiência concreta, material, que se encarna nos corpos. Por ser um trabalho imaginativo e inventivo, a experiência musical encontra a política, nessa abertura de criação de novas ficcionalidades, já que

a política e a arte, tanto quanto os saberes, constroem "ficções", isto é, rearranjos materiais dos signos e das imagens, das relações entre o que se vê e o que se diz, entre o que se faz e o que se pode fazer. (Rancière, 2009b, p. 59)

A arte pode tensionar o sentir, perturbar o modo como os espaços e corpos são distribuídos, abrindo para a experiência de um tempo outro, em que se ignoram as distâncias hierárquicas operantes, uma vez que "uma obra de arte vivenciada pode efetivamente ampliar a nossa concepção de algum campo de fenômenos, levar-nos a ver esse campo com novos olhos" (Vigotski, 1924/2010, p. 342).

Nesse sentido, compreendemos que o fazer musical, ou o ato de musicar, como proposto por Small $(1998,1999)$, é muito mais complexo do que considerar a música como um meio de comunicar emoções. O termo original em inglês escolhido por Small é musicking $(1998,1999)$. Com isso, o autor propõe pensar que a música só se dá em ato, ou seja, o foco está no fazer musical, por isso, ele propõe tratar a música como verbo, e não como substantivo. O musicar se aproxima muito mais de um encontro em que, quando se experienciam diferentes formas de atuação, se experienciam também as relações de mundo, como imaginamos que são e como desejamos que venham a ser. Assim, na arte reside a possibilidade de "criação de situações adequadas para modificar nossos olhares e nossas atitudes em relação a esse ambiente coletivo” (Rancière, 2010a, p. 18). Desse modo, a arte não somente provoca efeitos, ela cria afecções, interferindo no campo de possibilidades de ser, pensar e agir dos sujeitos. Há aí a marca que nos é cara, a possibilidade de projetar-se a outros possíveis. Compreendendo que quanto mais aberta a mover questões e respostas, mais potente se faz a arte (Rancière, 2010b; Vigotski, 1925/1998, 1924/2010). 


\section{Considerações finais}

A arte não é uma esfera separada da vida. Há uma potência na arte, pois ela pode tensionar lugares instituídos, provocando fissuras nas formas cristalizadas de ver, pensar e escutar o humano, interferindo assim na configuração sensível do território.

Ao transitarem pelos movimentos de desidentificação e identificação impossível, musicoterapeutas tomam uma atitude radical em relação ao seu campo de saber e prática e em relação às existências que partilham o mundo comum. Por meio desses movimentos constituintes dos processos de subjetivação política, as ações de musicoterapeutas na América Latina podem mediar encontros que perturbem os regimes postos de visibilidade, audibilidade e pensabilidade. Assim, argumentamos que determinados encontros, mediados pelo fazer musical, podem promover processos de emancipação, por possuírem a potência de tensionar lugares identitários, configurações sensíveis e, dessa forma, promover atos de verificação da igualdade.

Consideramos que mesmo dentro do campo de ações e saberes de uma Musicoterapia de base social e comunitária, os movimentos que lançam a processos de subjetivação política não estão claramente postos, o que nos moveu a trabalhar neste artigo não somente com os aspectos que mais emergem em nosso campo de interesse, mas sim com essas pequenas fagulhas de movimentos que abrem a possibilidade de ampliar as formas de se criar Musicoterapia.

Com esta escrita, refletimos que os processos de subjetivação política podem ser experienciados por qualquer uma das pessoas envolvidas nos encontros, sejam as pessoas partícipes ou os/as musicoterapeutas, uma vez que, por meio de experiências que verifiquem o princípio de igualdade, alarga-se o campo de possíveis para todo/a e qualquer $\mathrm{um} / \mathrm{a}$.

Nosso desejo é que este artigo possa contribuir com o processo de composição de cenas potentes na perturbação do campo convencionalmente posto dos saberes e fazeres musicoterápicos. Consideramos que a grande aposta da Musicoterapia sob uma perspectiva social e comunitária é mediar encontros em que as pessoas possam colocar em comum o desejo de viver outra vida, de sonhar e, quiçá, anunciem assim outros mundos possíveis.

\section{Nota}

1 As pessoas entrevistadas assinaram o Termo de Consentimento Livre Esclarecido e esta pesquisa obteve aprovação do Comitê de Ética por meio do Certificado de Apresentação para Apreciação Ética - CAAE de número 78435617.1.0000.0121. 


\section{Referências}

Arndt, Andressa, Cunha, Rosemyriam, \& Volpi, Sheilla (2016). Aspectos da prática musicoterapêutica: contexto social e comunitário em perspectiva. Psicologia Ẽ Sociedade, 2(28), 387-395. Recuperado de http://dx.doi.org/10.1590/1807-03102016v28n2p387

Arndt, Andressa \& Maheirie, Kátia. (2019). Musicoterapia: dos fazeres biomédicos aos saberes sociocomunitários. Rev. Polis e Psique, 9(1), 54-71. Recuperado de https://seer.ufrgs. br/PolisePsique/article/view/80215/pdf?fbclid=IwAR3X31CAAB05PCKqmvKSkxQNEN ePn7 U9bz2CxrbHgYgSLfJIvwcBio21Gw

Aragon, Leandro (2019). Improvisação livre: política da música e experimentação musical. Appris.

Blacking, John (2007). Música, cultura e experiência (André. K. M. Schouten, trad.). Cadernos de Campo, $16(16), 201-218$.

Bruscia, Kennedy. (2016). Definindo Musicoterapia. Barcelona Publishers.

Costa, Luis. (2014). O corpo das nuvens: o uso da ficção na Psicologia Social. Fractal, Revista de Psicologia, 26(nspe.), 551-576. Recuperado de http://www.scielo.br/pdf/fractal/ v26nspe/1984-0292-fractal-26-spe-0551.pdf

Cunha, Rosemyriam (2016). Musicoterapia Social e Comunitária [resumo expandido]. In União Brasileira de Associações de Musicoterapia (Org.), Anais do VI Congresso Latino Americano de Musicoterapia - CLAM (pp. 55-60). Florianópolis: UBAM.

Maheirie, Kátia (2003). Processo de criação no fazer musical: uma objetivação da subjetividade, a partir dos trabalhos de Sartre e Vygotsky. Psicologia em Estudo, 8(2), 147-153.

Marques, Angela \& Prado, Marco A. M. (2018a). O método da igualdade em Jacques Rancière: entre a política da experiência e a poética do conhecimento. Revista Mídia e Cotidiano, 12(3), 7-32.

Marques, Angela \& Prado, Marco, A. M. (2018b). Diálogos e dissidências: Michel Foucault e Jacques Rancière. Appris.

Oselame, Mariane \& Carvalho, Fernanda (2013). A pesquisa em musicoterapia no cenário social brasileiro. Revista Brasileira de Musicoterapia, XIV(14), 67-80.

Paulon, Simone \& Romagnoli, Roberta (2010). Pesquisar, Intervir, Cartografar: melindres e meandros metodológicos. Estudos e Pesquisas em Psicologia, 10(1), 85-102.

Rancière, Jacques (1996). O desentendimento. Editora 34.

Rancière, Jacques (2002). O mestre ignorante. Cinco lições sobre a emancipação intelectual. Autêntica.

Rancière, Jacques (2009a). A few remarks on the method of Jacques Rancière. Parallax, (15)3, 114-123.

Rancière, Jacques (2009b). A partilha do sensível. Estética e política. Editora 34.

Rancière, Jacques (2010a). A estética como política. Devires - Cinema e Humanidades, (7)2, 14-36.

Rancière, Jacques (2010b). O espectador emancipado (Daniele Ávila, trad.). Urdimento Revista de Estudos em Artes Cênicas. 1(15), 107-122.

Rancière, Jacques (2014a). As margens do político. KKYM. 
Rancière, Jacques (2014b). El Metodo de la Igualdad: conversaciones con Laurent Jeanpierre y Dork Zabunyan. Nueva Visión.

Rancière, Jacques (2018). A política é imaginação. Recuperado de http://www.ihu.unisinos. $\mathrm{br} / 78$-noticias/581209-a-politica-e-imaginacao-entrevista-com-jacques-ranciere

Small, Christopher (1998). The meanings of performing and listening. Wesleyan University.

Small, Christopher (1999). El musicar: um ritual em el espacio social. Conferencia pronunciada en el III Congreso de la Sociedad Ibérica de Etnomusicología. (Benicàssim, 25 de mayo de 1997). Revista Transcultural de Música, 4. Recuperado de https://www.sibetrans.com/trans/ articulo/252/el-musicar-un-ritual-en-el-espacio-social

Vigotski, Lev Semiónovich (1998). Psicologia da arte. Martins Fontes. (Original publicado em 1925)

Vigotski, Lev Semiónovich (2010). A educação estética. In Psicologia Pedagógica (P. Bezerra, trad., pp. 321-345). Martins Fontes. (Original publicado em 1924)

Vigotski, Lev Semiónovich (2014). Imaginação e criatividade na infância. (João P. Fróis, trad.). Martins Fontes. (Original publicado em 1930) 


\section{ANDRESSA DIAS ARNDT \\ http://orcid.org/0000-0002-7445-3374}

Doutora em Psicologia pela Universidade Federal de Santa Catarina (2019). Professora Adjunta na Universidade Estadual do Paraná - UNESPAR. Graduada em Musicoterapia pela Universidade Estadual do Paraná UNESPAR.

E-mail: andressa.d.arndt@gmail.com

\section{KÁTIA MAHEIRIIE}

https://orcid.org/0000-0001-5226-0734

Doutorado em Psicologia (Psicologia Social) pela Pontifícia Universidade Católica de São Paulo (2001). Professora Titular da Universidade Federal de Santa Catarina, Florianópolis/SC.

E-mail: maheirie@gmail.com

\begin{tabular}{|c|c|}
\hline Histórico & $\begin{array}{l}\text { Submissão: 30/03/2020 } \\
\text { Revisão: 04/09/2020 } \\
\text { Aceite: 20/09/2020 }\end{array}$ \\
\hline $\begin{array}{l}\text { Contribuição } \\
\text { dos autores }\end{array}$ & $\begin{array}{l}\text { Concepção: A.D.A.; K.M. } \\
\text { Coleta de dados: A.D.A. } \\
\text { Análise de dados: A.D.A.; K.M. } \\
\text { Elaboração dlo manuscrito: A.D.A., K.M. } \\
\text { Revisões críticas de conteúdo intelectual importante: } \\
\text { A.D.A., K.M. } \\
\text { Aprovação finall do manuscrito: K.M. }\end{array}$ \\
\hline $\begin{array}{l}\text { Aprovação, ética } \\
\text { e consentimento }\end{array}$ & $\begin{array}{l}\text { Esta pesquisa obteve aprovação do Comitê de Ética. Certificado de } \\
\text { Apresentação para Apreciação Ética: } 78435617.1 .0000 .0121 .\end{array}$ \\
\hline Financiamento & $\begin{array}{l}\text { O presente trabalho foi realizado com apoio da Coordenação de } \\
\text { Aperfeiçoamento de Pessoal de Nível Superior - Brasil (CAPES) - Código } \\
\text { de Financiamento } 001\end{array}$ \\
\hline
\end{tabular}

